\title{
The Immediate Results of Percutaneous Balloon Aortic Valvuloplasty in Patients with Congenital Aortic Valvular Stenosis
}

\author{
Abdulhadi Hameed. A. Al Kaaby * \\ Talaat A. Al Jarrah \& Jasim Nasir Alkhalidi ** \\ * Interventional Cardiologist in Ibn- Al Bitar Cardiac Center. \\ ** Interventional Cardiologist in Nasiriyah Heart Center.
}

\begin{abstract}
Objective: To assess the immediate-term effectiveness of percutaneous balloon aortic valvuloplasty (PBAV) for congenital aortic stenosis (AS).

Design: Early clinical and instrumental evaluation of 34 consecutive PBAV performed from 2001 to 2007.

Setting: A tertiary referral center for heart diseases (Ibn Al-Bitar Cardiac Center).

Patients: Thirty-four patients with congenital valvular AS, twenty-five males and nine females.

Interventions: PBAV using Tayshak balloons of different sizes and lengths.

Main outcome measures: Doppler and peak to peak pressure gradient (PG) across the aortic valve (AV) before and after valvuloplasty, the percent of PG reduction post dilatation, left ventricular (LV) systolic and diastolic pressures before and after valvuloplasty, number of the aortic cusps, degree of aortic regurgitation (AR) before and after valvuloplasty, left ventricular systolic function before and after valvuloplasty, associated anomalies, and the need for emergency surgery were the main outcome measures.
\end{abstract}


Results: The peak to peak instantaneous PG across the AV was reduced acutely from $102 \pm 42.7$ (20 - 200) mm Hg to $40 \pm 25.5$ (10-140) mm Hg $(p<0.001)$, left ventricular systolic pressure was reduced from $196 \pm 48.57$ $(70-280) \mathrm{mm} \mathrm{Hg}$ to $133 \pm 35.45(65-240) \mathrm{mm} \mathrm{Hg}(\mathrm{p}<0.001)$ and both are statistically significant. Three patients had inadequate relief of obstruction but in one of them it was mainly due to subaortic obstruction and two patients had severe $A R$, one of them with acute pulmonary edema and required surgical $A V$ repair.

PBAV produced a gradient reduction $\geq 50 \%$ in 29 patients, six patients having a residual peak to peak gradient of $>50 \mathrm{~mm} \mathrm{Hg}$ and in one of whom the remaining PG was $70 \mathrm{~mm} \mathrm{Hg}$ which was mainly subvalvular (50 $\mathrm{mm} \mathrm{Hg}$ ).

Six patients had bicuspid AV while the other patients had tricuspid valve. Six had associated anomalies. There was no mortality during the procedure. Severe AR reported in two patients and moderate AR occurred in five patients.

One significant complication (acute pulmonary edema) occurred immediately after the dilatation and surgery was done for that patient after few days. Two serious complications occurred during the procedure which responded to routine resuscitation.

There was a residual maximum Doppler gradient of $<30 \mathrm{~mm} \mathrm{Hg}$ in 12 patients, $\geq 60 \mathrm{~mm} \mathrm{Hg}$ in four (one of them had mainly subvalvular gradient) and between 30 to $48 \mathrm{~mm} \mathrm{Hg}$ in the others.

Twenty one patients developed new AR (62\%), in fourteen of them (41\%) it was mild.

Conclusions: PBAV is an effective procedure and offers a good palliation for congenital AS.

Keywords: aortic valve disease; percutaneous balloon valvuloplasty; interventional catheterization.

\section{Introduction}

Congenital AS is characterized by narrowing of the aortic valve orifice, leading to left ventricular hypertrophy and predisposing the patient to exercise intolerance and myocardial dysfunction. ${ }^{(1) \&(2)}$ Clinical evaluation of congenital obstruction to left ventricular outflow seeks to establish the 
presence and the degree of obstruction and the level and morphologic type. ${ }^{(3)}$ The five varieties of congenitally abnormal aortic valves are based on the number and types of cusps and commissures. $^{(4)}$

Valvular AS is the most common type of AS that consists 65 to $75 \%$ of left ventricular outflow abnormalities (1)\&(2) and accounts for $3 \%$ to $6 \%$ of patients with congenital cardiovascular defects. Males are four times more likely to have valvular AS than are females. ${ }^{(5) \&(6)}$ The prevalence of associated cardiovascular anomalies may be as high as $20 \% .{ }^{(7)}$ Patent ductus arteriosus and coarctation of the aorta occur more frequently with valvular AS, and all three of these lesions may coexist. ${ }^{(5)}$

\section{Patients and Methods}

\section{Study Group (Patients)}

This is a retrospective study of thirty-four patients, it reviews all patients with congenital (AS) who required intervention in $\mathrm{Ibn} \mathrm{Al}$ Bitar Cardiac Center from the twenty first of April 2001 to the first of September 2007.
The population included 25 males (74\%) and 9 females (26\%). The ages of the patients' ranges from 28 days to 17 years (mean 7 years) and weights ranges from 3 to $70 \mathrm{Kg}$ (mean $23 \mathrm{Kg}$ ).

\section{Criteria for Dilatation}

\section{Inclusion Criteria:}

(1) Critical AS was present, defined by clinical (presence of low cardiac output, cardiogenic shock, congestive heart failure) and echocardiographic criteria (morphological evidence of left ventricular hypertrophy, with depression of left ventricular function (LVF), irrespective of the transvalvular gradient). A maximum $\mathrm{AV} P \mathrm{PG}$ of more than $70 \mathrm{~mm} \mathrm{Hg}$ with preserved LVF was also an independent indication for balloon valvuloplasty.

(2) A resting peak systolic AV PG of $70 \mathrm{~mm} \mathrm{Hg}$ or greater, or a gradient of $50 \mathrm{~mm} \mathrm{Hg}$ or greater with associated symptoms (heart failure or syncope).

\section{Exclusion Criteria}

Balloon dilatation was not performed when AR of more than mild degree was present also 
PBAV was not done if the patient had significant associated cardiac anomalies that require surgical treatment.

\section{Vascular}

Balloon dilatation was performed retrograde via the percutaneous femoral artery (FA) approach in all cases.

\section{Balloon Dilatation Technique (Valvuloplasty Procedure)}

All procedures were performed under general anesthesia. A left ventricular cineangiogram and an aortogram were performed before valvuloplasty. Intravenous heparin (100 U/kg) was administered routinely following FA cannulation and with the introduction of the balloon. The annulus diameter was determined from preprocedure echocardiogram or from intraprocedural angiography. One balloon was used in 19 patients (56\%), two balloons were used in 9 cases (26\%), three balloons in 5 (15\%) and four subsequently in one patient (3\%).

The balloon catheter was selected to yield a ratio of balloon diameter to annulus diameter of 80-125\% (99.5\%). Repeat hemodynamic measurements and an aortogram were performed after valvuloplasty.

\section{Methods}

We evaluated Doppler AV PG and the degree of $A R$ on colour Doppler imaging, peak to peak systolic AV PG and the degree of $A R$ at angiography before and after PBAV.

The aortic annulus was measured by bidimensional echocardiography and cineangiography, using the catheter size to correct for magnification. Initial balloon size was $63-100 \%$ of the angiographically or echocardiography measured aortic annulus.

If inadequate relief of the gradient was obtained (less than $50 \%$ reduction) in the presence of good systolic function or no valve waist was seen, and in the absence of more than mild AR, serial dilatation with a larger size balloon was performed, to a maximum of $125 \%$.

\section{AR Assessment}

The method that we used for quantifying $A R$ (echocardiographically or angiographically) is that of Moore et al (8) and according to the ACCF/ASE/ACEP/ASNC/SCAI/SCCT/ 
SCMR 2007 Appropriateness Criteria $^{(9)}$, using a scale of 0 to 3 : 0 , absent;

1 , mild;

1-2, mild to moderate;

2, moderate;

3 , severe.

\section{Definition of Successful PBAV}

(1) With preserved LVF, success was defined as a gradient reduction of $50 \%$ or more, or a maximum residual gradient of $50 \mathrm{~mm} \mathrm{Hg}$ or less.

(2) With impaired LVF, it was defined as immediate improvement of LVF, irrespective of the gradient (because almost it is under estimated), employing an adequate balloon to annulus ratio.

(3) Patients did not die.

(4) Patient did not develop severe AR.

\section{Statistical Analysis}

Data and results were expressed as range and medianstandard deviation (SD). The Chisquare test was used to test the level of significance. A $p$ value $<0.05$ was taken as significant.

\section{Discussion}

Balloon dilatation of congenital valvular AS is a relatively effective mean of palliation and carries a low risk of serious complications in most patients.

\section{Population}

The age distribution of the patients is wide (28 days-17years) and was similar to many other previous studies like Sholler et al. ${ }^{(10)}$

\section{Immediate Results}

A successful outcome was achieved in $88 \%$ of the patients, in accordance with data reported by other investigators. ${ }^{(8),(11) \&(12)}$

The failure rate was $12 \%$ (four cases from all thirty-four aortic valvuloplasties), nearly similar to the failure rate of O'Connor et al which was $9 \%{ }^{(13)}$, one of the failure patients had bicuspid valve, so it was higher $17 \%$ in the bicuspid valves $(1 / 6)$ while it was $11 \%$ in the tricuspid valves $(3 / 28)$.

\section{Gradient Reduction}

The percent of $P G$ reduction was $62.5 \pm 14.6 \%(25-89 \%)$ and the PG after dilation was $40 \pm 25.5$ $(10-140) \mathrm{mm} \mathrm{Hg}$. These results are comparable with other reviews. (8), (10), (13), (14), (15),(16),(17),(18), (19), (20) \&(21) 


\section{Left Ventricular Pressure}

\section{Reduction}

The left ventricular systolic pressure fell from $196 \pm 48.57$ (70 - 280) $\mathrm{mm} \mathrm{Hg}$ to $133 \pm 35.45$ (65 240) $\mathrm{mm} \mathrm{Hg}$, similar to what O'Connor et al ${ }^{(13)}$ was observed.

The left ventricular end diastolic pressure did not change significantly where it decreased from $20.4 \pm 11.2(8-50) \mathrm{mm} \mathrm{Hg}$ to $18.4 \pm 9.6(5-45) \mathrm{mm} \mathrm{Hg}(p>0.1)$.

\section{Doppler gradient}

Maximum peak instantaneous Doppler gradient across the AV decreased from $91 \pm 28$ (40-160) $\mathrm{mm} \mathrm{Hg}$ to $38 \pm 19(20-100) \mathrm{mm}$ $\mathrm{Hg}$.

Left ventricular systolic ejection fraction remained unchanged after valvuloplasty (60 $\pm 12 \%$ vs $62.5 \pm 10.5 \%, p>0.1$ ), , was comparable to what was Galal et al ${ }^{(16)}$ reported and this was mostly because the LV EF need more time to improve after the procedure.

\section{Complications}

\section{Aortic Insufficiency}

In our study it is the major complication and was relatively high (6\%), similar to the O'Connor's et al series. ${ }^{(13)}$ However, only one of them required surgical intervention, similar to Galal et al series. ${ }^{(16)}$

\section{Surgical Intervention}

Surgery was performed in only one patient (3\%), and it was aortic valve repair.

\section{Survival Rate}

The survival rate in our study was $100 \%$.

\section{Conclusions}

PBAV is an effective technique, which can be employed in childhood and it provides effective and excellent immediate pressure gradient reduction in infants, children and adolescents with congenital valvular AS. The current study has shown that acceptable pressure gradient reduction without severe $A R$ in the majority of children.

Since PBAV does not require thoracotomy or cardiopulmonary bypass and is associated with a shorter hospital stay compared with surgery, it should replace surgical valvotomy as the treatment of choice for children and adolescents with congenital valvular AS.

As PBAV can delay further intervention for several years provided it results in clinically effective dilatation, it offers the prospect of palliation for AS in children and adolescents. 
However, as progressive AR and re-development of pressure gradient is not uncommon, even after clinically effective PBAV, we should not delay more definitive surgical treatment.

\section{References}

(1) Laston LA. Aortic stenosis valvar, supravalvular and fibromuscular subvalvar. In: Garson Al, Bricker IT, Mc Namara DG, editors. The science and practice of pediatric cardiology.1st ed. Lea and Febiger; 1998. p. 1257-1273.

(2) Fiooman EF. Aortic stenosis. In: Adams FH, Emmanouilides GC, editors. Heart diseases in infants, children and adolescents. 2nd ed. Baltimore: Williams and Wilkins; 1995. p. 439-443.

(3) Waller B., Howard J., Fees S: Pathology of aortic valve stenosis and pure aortic regurgitation. Part II Clin Cardiol 17:85,150, 1994.

(4) Robert WC: Valvular, subvalvular and supravalvular aortic stenosis. Cardiovas Clin 5:104, 1973.

(5) Allen H. D., Clark E. C., Gutgesell H. P., and Driscoll D. J. MOSS and ADAMS' Heart Disease in infants, Children, and
Adolescents $6^{\text {th }}$ edition(2001):Section III Part G: 970-987.

(6) Hoffman JIE (1969) The natural history of congenital isolated pulmonic and aortic stenosis. Annu Rev Med 20:15-28.

(7) Brunwald E., Goldblatt A., Aygen MM, et al. Congenital aortic stenosis. I: Clinical and hemodynamic findings in 100 patients. Circulation 1963; 27:426462.

(8) Moore $P$, Egito E, Mowrey $H$, Perry SB, Lock JE, Keane JF. Midterm results of balloon dilation of congenital aorticstenosis: predictors of success. J Am Coll Cardiol. 1996; 27(5): 1257-1263.

(9) Douglas et al. JACC Vol. ACCF/ASE/ACEP/ASNC/SCAI/SCCT/ SCMR 2007 Appropriateness Criteria for Transthoracic and Transesophageal

Echocardiography JACC Vol. $x x$, No. $x, 2007$.

(10) Sholler G.F, Keane JF, Perry SB, Sanders SP, Lock JE (1988) Balloon dilation of congenital aortic valve stenosis. Circulation 1988; 78: 351-360. 


\section{Email:utjmed@utq.edu.iq}

(11) Gatzoulis MA, Rigby ML, Shinebourne EA, and Redington AN Contemporary results of balloon valvuloplasty and surgical valvotomy for congenital aortic stenosis. Arch. Dis. Child., July 1, 1995; 73(1): 66-9.

(12) Zeevi B, Keane JF, Castaneda $A R$, Perry SB, Lock JE: Neonatal critical valvular aortic stenosis: $A$ comparison of surgical and balloon dilatation therapy. Circulation 80:831-839, 1989.

(13) O'Connor BK, Beckman RH, Rocchini AP, Rosenthal A. Intermediate-term effectiveness of balloon valvuloplasty for congenital aortic stenosis. A prospective follow-up study. Circulation 1991; 84:732-738.

(14) Borghi A, Agnoletti G, Valsecchi O, Carminati M. Aortic balloon dilatation for congenital aortic stenosis: report of 90 cases (1986-98), Heart 1999; 82:e10 (December).

(15) Keane H. JF, Fellows KE, et al. Balloon dilation of the aortic valve: studies in normal lambs and in children with aortic stenosis. J Am Coll Cardiol 1987; 9:816-22.

(16) Galal O, Rao PS, Al Fadley F, et al. Follow-up results of balloon aortic valvuloplasty in children with special reference to causes of late aortic insufficiency. Am Heart J 1997; 133:418-27.

(17) Lababidi Z., J Wu and JT Walls, Percutaneous balloon aortic valvuloplasty: results in 23 patients, Am J Cardiol 54 (1984), pp. 194-197.

(18) Tomita H.; Echigo S.; Kimura K. ; Kobayashi T.; Nakanishi T.; Ishizawa R.; Akagi T.; Ino T.; Harada Y.; Kado H. \& Yagihara T., Balloon Aortic Valvuloplasty in Children, J pn Circ J 2001; 65: 599 -602 .

(19) Choy M, Beekman RH, Rocchini AP, Crowley DC, Snider $A R$, Dick $M$, Rosenthal A: Percutaneous balloon valvuloplasty for valvular aortic stenosis in infants and children. Am J Cardiol 1987; 59:1010-1013.

(20) Walls JT, Lababidi Z, Curtes JJ, Silver D: Assessment of percutaneous balloon pulmonary and aortic dilation. I Thorac Cardiovasc Surg 1984; 88:352-356.

(21) Rupprath G, Neuhaus KL: Percutaneous balloon aortic valvuloplasty in infancy and childhood. Am J Cardiol 1985; 55:1855-1856 
Thi-Qar Medical Journal (TQMJ): Vol.(13), No.(1), 2017

Email:utjmed@utq.edu.iq

Web Site: $\underline{\text { https://jmed.utq.edu.iq }}$

\section{النتائج الاولية لتوسيع الصمام الأبهري بالبالون بواسطة القسطرة عن طريق الجلد للمرض المصابين بتضيق الصمام الأبهري الولادي الصني}

الخلاصة

هيكل الدراسة \& هدف الدراسة:

بيان الفائدة الأولية لعملية توسيع الصمام الأبهري بالبالون بواسطة القسطرة عن طريق الجلد لعلاج تضيق الصمام

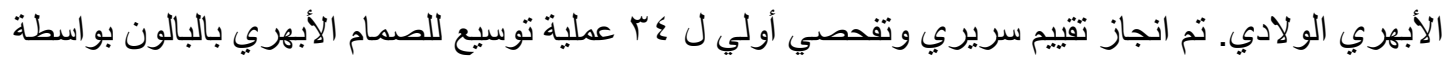

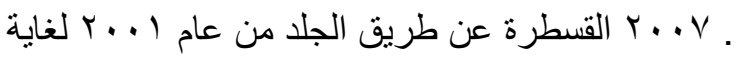

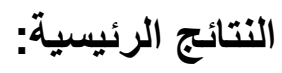

فرق الضغط القمي خلال الصمام الأبهري قبل و بعد عملية التصليح ، نسبة تقليل فرق الضغط بعد عملية التوسيع، ضغط البطين الأيسر التقلصي و الأنبساطي قبل و بعد العملية، عدد أوراق الصمام الأبهري، درجة تسريب الصمام

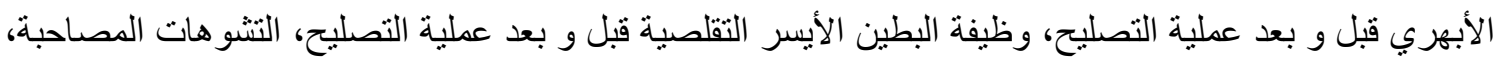
الأحتياج الى الجر احة الطارئة كانت أهم القياسات لتحديد النتيجة.

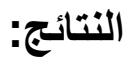

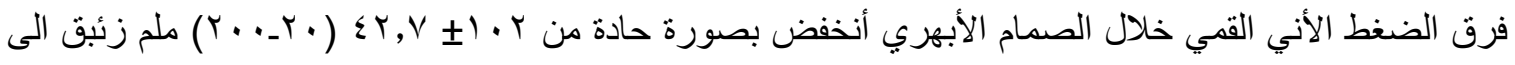

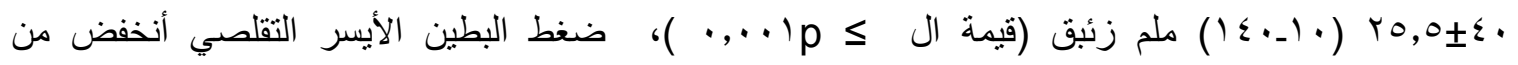
9

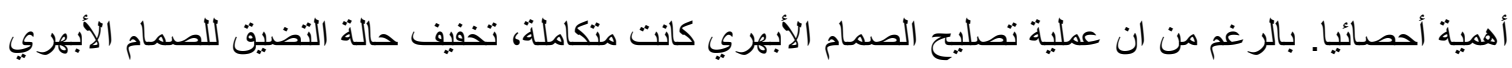

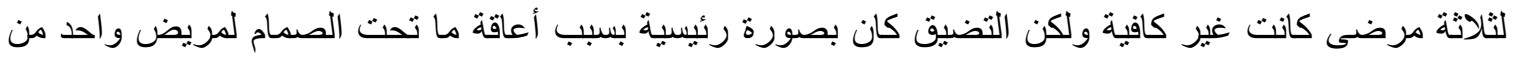

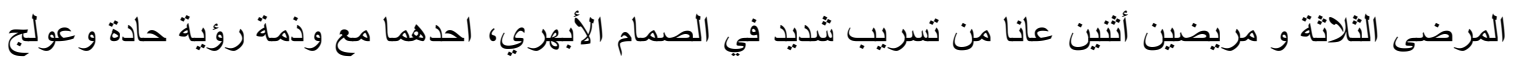

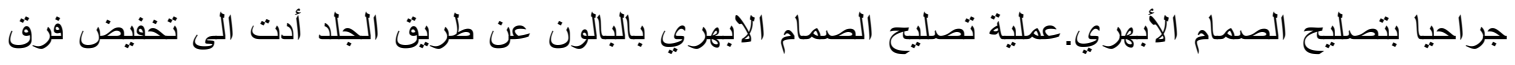

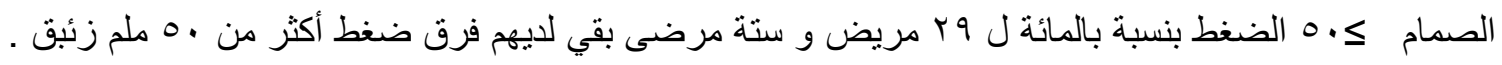

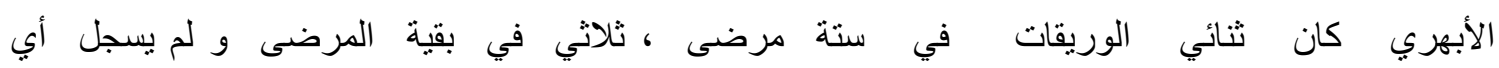
صمام أحادي الغشاء 
Thi-Qar Medical Journal (TQMJ): Vol.(13), No.(1), 2017

Email:utjmed@utq.edu.iq Web Site: https://jmed.utq.edu.iq

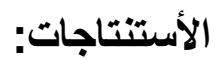

عملية تصليح الصمام الأبهري بالبالون مفيدة وتعرض تلطيف جيد لتضيق الصمام الأبهري الولادي. 